\title{
THE WICKED PROBLEMS OF GLOBAL SUSTAINABILITY NEED WICKED (GOOD) LEADERS AND WICKED (GOOD) COLLABORATIVE SOLUTIONS
}

SANDRA WADDOCK

Boston College

Chestnut Hill, Massachusetts, U.S.A.

waddock@bc.edu

Abstract. Making a difference in the pursuit of a more sustainable world increasingly requires the ability to contend successfully with the wicked problem that is sustainability, and this shift needs to happen at the societal as well as the organizational level. Dealing successfully with issues of sustainability means creating greater system resilience and using resources more wisely, which means working successfully across boundaries, be they sector, organizational, policy, or functional ones. Wicked problems are poorly formulated, confusing, and have many different constituents or stakeholders with conflicting values. This article argues that developing wicked (good) leadership that is collaboratively oriented and wicked (good) solutions that enhance system resilience are two potential strategies for creating change to reduce systemic problems associated with sustainability. Although these approaches do not deal with the problem of resource overuse, they may provide a basis for generating more sustainable approaches to resource use.

In the late 1960s, Churchman, citing his colleague (Rittel \& Webber, 1973), defined wicked problems as "that class of social system problems [that] are ill-formulated, where the information is confusing, where 
there are many clients and decision makers with conflicting values, and where the ramifications in the whole system are thoroughly confusing" (Churchman, 1967). Systems theorist Ackoff further noted that wicked problems are inherent in systems where every problem is linked to and inextricably interacts with others. Ackoff, who called such systems "messes," noted that they are too complex or difficult to be resolved by single entities (Ackoff, 1974). Within any mess are any number of wicked problems, which themselves are complex, intractable, and difficult to resolve.

If ever there was a wicked problem, the sustainability-or, more accurately, unsustainability-of the current world system is one. This article argues that coping with the wicked problem of sustainability in the current system requires wicked good solutions, which involve generating greater system resilience along with reduced ecological pressures, and wicked good leadership, which means different types of leadership skills at the societal, in addition to the organizational, level than are now common. These shifts arise because collapsing boundaries among sectors and institutions mean that collaborative approaches are increasingly needed in order to find new ways forward in dealing with the sustainability crisis (Gilding, 2011; Hart, 2007, 2006; McKibben, 2010, 2012; Senge, Smith, Kruschwitz, Laur, \& Schley, 2008).

\section{SUSTAINABILITY AS WICKED PROBLEM}

Consider for a moment the complexities surrounding today's sustainability crisis. Climate change, disturbed weather patterns, collapsing ecosystems, species extinction, pollution from industrial farming practices, deforestation, desertification, huge oceanic dead zones, and numerous other ecological issues only begin to describe the challenges embedded in creating a more sustainable civilizational strategy for humanity (Brown, Brown, Plan B 3.0, \& Earth Policy Institute, 2009; Intergovernmental Panel on Climate Change, 2007; McKibben, 2010; Waddock, 2011). Complicate this ecological scenario with a global financial market that could be characterized as nothing less than a gambling casino run amuck, for which regulation is limited or failing, and that operates across national, organizational, and institutional boundaries. Add in social problems, such as a disastrous housing market fraught with fraud in many developed nations, a growing gap between rich and poor around the globe, including in developed nations like the U.S., and too many people seeking work in economies with too few jobs, among many other issues. Combine all of these elements with the inherently unsustainable economic/ business imperative of constant growth, consumption, and materialism in a world of limited resources (Ehrenfeld, 2008; Jackson, 2012). Finally, 
complicate things even further by recognizing the emerging reality that organizational, societal, and institutional boundaries seem to be rapidly diminishing, creating difficulties in communicating and managing change across entities that are increasingly interlinked and yet have different norms, standards, and practices (Durant \& Legge, 2006).

The sustainability problem in all of its manifestations is, by nature, a wicked problem. Wicked problems in the classic definition by Rittel and Webber have the following characteristics:

- $\quad$ There is no definitive formulation as each problem can be conceived as a symptom of other problems (and yet the process of solving the problem is identical to understanding it).

- $\quad$ There are multiple possible solutions and no stopping rule (i.e., there are no specific criteria to use to determine when "a" or "the" solution is found).

- $\quad$ Solutions are not true-or-false but good-or-bad (or better or worse, or good enough), and there is no definitive solution or end to the problem, hence ...

- $\quad$ there is no immediate and no ultimate test of a solution (waves of consequences follow over an unbounded time period from any attempted solution, sometimes with unintended consequences).

- $\quad$ Since each problem is essentially unique, every solution is a "one shot operation" with no chance to learn by trial and error; therefore, every effort counts significantly and the planner has "no right to be wrong" (because solutions leave "traces" that cannot always readily be undone).

- $\quad$ There are numerous stakeholders, social complexities, and differing points of view, and solutions frequently require system reform and changed behavior (Rittel \& Webber, 1973).

A simpler formulation of wicked problems is that they are unstructured, cross-cutting, and relentless (Weber \& Khademian, 2008). Sustainability, considered broadly, involves ecological sustainability, and it also encompasses the long-term viability of organizations and societies and, in particular, human civilization (c.f., Batie, 2000). The focus of the present discussion is at the societal level, where significant changes 
in leaders' mindset, orientation of institutions toward growth, and in the ecology are clearly needed. The situation is complicated by dissolving sector, organizational, disciplinary, and institutional boundaries that exacerbate the problems the world is facing and make them more complex and intractable-that is, more wicked. In such contexts, leadership capabilities, practices, and behaviors (Ferlie, Fitzgerald, McGivern, Dopson, \& Bennett, 2011; Levin, Cashore, Bernstein, \& Auld, 2012) that are more attuned to collaborative strategies across and, of course, within institutions and organizations will be important because working across boundaries of all sorts is increasingly necessary. Similarly, understanding a core concept related to enhancing system diversity-and hence resilience-at the ecological and societal level, rather than diminishing it as is currently happening, may be a key to dealing with the type of wicked problems that the sustainability crisis presents to societies.

The consequence of collapsing boundaries and increasing complexity generates what Levin, Cashore, Berstein \& Auld (2012) call a "super wicked problem," with four key features that all apply to the sustainability crisis. One such feature is short time horizon for resolution, i.e., climate change is here and getting worse; action is needed sooner rather than later. The second feature of super wicked problems is that there is no central decision-making authority, which is certainly true of sustainability because governments, multilateral organizations and institutions, businesses, NGOs, and citizens are all involved in various ways. The third characteristic is that the problem creators are the same as the problem solvers, and from the list in the previous sentence, it is apparent that this is the case for sustainability. The fourth characteristic is that actors irrationally discount the future, i.e., little consideration is given to the needs of the future, despite their centrality in the Brundtland Commission's definition of sustainability (Brundtland Commission, 1987). Indeed, Levin et al. characterize the sustainability crisis as a super-wicked tragedy because existing governance mechanisms and policies are almost wholly inadequate to cope with them (Levin et al., 2012).

Wicked problems are obviously not new-they have always existed. Most social problems, for example, are wicked. But the complexities posed by the sustainability crisis within societies as a whole challenge humanity in new ways because of the scale and scope of the problems. Moreover, while the global connectedness of the world, the immediacy and visibility of that connectivity, the expansion of problems across boundaries, and the scale of many social-ecological issues means that there is increasing awareness of these wicked problems, their scope and intensity are also increasing. Leaders in business, government, and civil society are struggling to figure out how to cope. In response to this, the boundary quandary provides a useful context for elaborating ways in 
which system resilience and leadership can be used in the face of the sustainability crisis.

\section{THE BOUNDARY QUANDARIES OF WICKED PROBLEMS}

In today's world, the complexity of managing across sector boundaries in collaborative initiatives has increased because sector, organizational, disciplinary, and institutional boundaries that once seemed clear are now rapidly dissolving. For any given enterprise, such boundary-less (or boundary-reduced) conditions increasingly exist externally in relation to other enterprises and other types of institutions, as well as internally across functions.

Evidence for the diminishment of boundaries abounds. For one thing, companies are increasingly taking on explicit social or public purposes (Matten, Crane, \& Chapple, 2003; Matten \& Crane, 2005; Moon, Crane, \& Matten, 2005) even while they continue profit maximization strategies. For example, Google states its purpose as "to organize the world's information and make it universally accessible and useful." ${ }^{1}$ Certainly, a clear assessment of the role that Google has played in changing the world would suggest that its provision of access to information could be defined as a public good, albeit with an underlying profit motive. Similarly, Facebook's mission "is to give people the power to share and make the world more open and connected." ${ }^{2}$

It is not just that some large public companies have taken on what might be viewed as a social agenda in their mission statements, but also that many of them have also initiated social enterprises that attempt to create what Emerson (2003) calls "blended value," Porter and Kramer call shared value (2011), and Austin and Seitanidi (2011) call creating shared value, that is, making a profit while simultaneously doing good (Van Tulder \& de Rosa, 2011). Group Danone, for example, has partnered with Grameen Bank to create Grameen Danone, an entity that has developed a special fortified yogurt product to supplement very poor children's diets. Consumer products giant Unilever has created a social enterprise called Project Shakti, which provides micro-credit and training for Indian women who then sell some of the company's products locally. Notably, there has also been an incursion of multinational and other large for-profit enterprises into domains once considered sacrosanct to the public sector,

${ }^{1}$ Google website, Company Information, http://www.google.com/about/corporate/ company/ (accessed Sept. 6, 2011).

${ }^{2}$ Facebook, https://www.facebook.com/facebook?v=infom (accessed Sept. 6, 2011). 
including education, health care, and environmental arenas, as part of what is often called corporate citizenship (Matten et al., 2003; Matten \& Crane, 2005; Moon et al., 2005). New types of enterprise are also arising in the form of B Corporations or for-benefit enterprises, which explicitly and deliberately blend social and economic value with sustainability values into their core purposes (Austin \& Seitanidi, 2011; Emerson, 2003; Emerson, 1999). Enterprises like EcoScraps ${ }^{3}$ and Freelancers Insurance ${ }^{4}$ are examples of such for-profit enterprises with a social (or blended) mission. So popular have such blended value enterprises become that Bloomberg BusinessWeek now profiles the top 25 annually. Other evidence for blurring (or collapsing) boundaries comes in the form of what has been called SEE Change (Waddock \& McIntosh, 2011) — change to a sustainable enterprise economy, emerging out of the process of what economist Joseph Schumpeter called creative destruction (Schumpeter, 1962).

From the civil society and governmental perspectives, there has also been a burgeoning of social enterprises started specifically as such, particularly since the publication of Prahalad and Hart's concept of the bottom of the pyramid (Hart, 2007; Prahalad \& Hammond, 2002; Prahalad, 2005). An emerging type of multi-sector and explicitly collaborative activity at the societal and global levels is the Global Action Network or GAN (Waddell, 2003, 2009). GANs are networks that include actors from different sectors with multiple perspectives coming together around wicked societal-level problems like sustainability, and frequently deal with problems that governments have failed to or cannot readily address, sometimes because they cross geographical or national boundaries. Issues of forest or marine stewardship, education, global corporate citizenship, and non-financial reporting have all been tackled by GANs, which produce public goods by taking action and building new relationships, processes, and tools through global, multi-level networks. The key is that the issues GANs contend with often fall within the domain of public policy but are not necessarily being dealt with in the GAN by governmental entities, though governments are not necessarily excluded from GANs either. GAN members typically come from a variety of settings and sectors and work collaboratively on creating systemic change, e.g., as the Forest Stewardship Council did by establishing standards for forest companies, or as the Global Reporting Initiative (GRI) has done by establishing globally accepted environmental, social, and governance (ESG) reporting standards (Waddell, 2009).

${ }^{3}$ For a description, see http://images.businessweek.com/slideshows/20110621/ america-s-most-promising-social-entrepreneurs-2011/slides/9 (accessed March 23, 2012).

${ }^{4}$ Forinformation, seehttp://images.businessweek.com/slideshows/20110621/americas-most-promising-social-entrepreneurs-2011/slides/12 (accessed March 23, 2012). 
All of these activities, and more that could be named, highlight the blurring of boundaries that provides a context in which issues of sustainability and leadership at the societal level are rising up. In this context, a collaborative orientation becomes increasingly important. This article argues that to effectively deal with this superwicked problem of sustainability created in part by the global trend towards collapsing boundaries, "wicked good" leadership and collaboration are needed.

\section{COLLABORATION IN THE CONTEXT OF WICKED PROBLEMS}

In any situation where there are wicked problems, there is no single solution that is feasible or considered to be the best way to go. Indeed, Rittel and Webber (1973) argue that scientific and possibly even rationalseeming solutions are unlikely with wicked problems in the social policy arena, as solutions almost by definition must be negotiated by different parties in a context of multiple possible paths going forward. Furthermore, each stakeholder group interested in the problem is likely to have a different perspective on both what the best outcome and what the best solution should be (van Bueren, Klijn, \& Koppenjan, 2003; Weber \& Khademian, 2008). As Ackoff (1974) pointed out, no single organization or entity can resolve messes or wicked problems. Solutions can come only from the interaction and engagement of multiple stakeholders, i.e., collaboration in trying to find a path forward.

Overall, dealing with wicked problems is more complex and difficult than dealing with more tractable single-issue problems. In fact, wicked problems may never be solved-but approaches can be taken collaboratively to bring about better outcomes. This article argues that dealing with the wicked problem of sustainability requires two core elements: creating greater system resilience for the natural environment and for humanity within the environment, and, as a consequence, rethinking leadership so that it is better suited to dealing with the complexities of collaborative approaches (Avery \& Hughes, 2012).

\section{Wicked (Good) Solution 1: Enhance System Resilience}

The collapsing of boundaries at the global and national levels, combined with the global reach of many multinational corporations, has created at least the appearance of one world, almost necessitating collaborative approaches for both large and smaller-scale initiatives. Digital technologies enhance interconnectedness, creating economies tightly linked to one another, as the meltdown of the global financial system in 2007-2008 aptly demonstrated. Industrial agriculture uses vast tracts 
of land to grow one crop-monocultures of corn and soybeans that find themselves in virtually all mass-produced food products today (Pollan, 2007). These crops also lend themselves to being wiped out or collapsing should soil overuse, disease, drought, or other devastating natural events hit (Diamond, 2005). Soil is depleted due to the overuse of pesticides and fertilizers, which in turn pollute local rivers, streams, and lakes, eventually running off into and further polluting the oceans. Multiple systems use these inputs for manufactured "food products," some of which have little nutritional value. The list goes on in connected systems that affect the health, wellbeing, and status of all.

Tightly interconnected systems that are linked with large-scale operations of various sorts are rigid in the sense that when one element fails, that failure has the potential to bring down the whole system. The threatened collapse of AIG during the 2008 global financial crisis demonstrated this in the economic sphere. In the sustainability sphere, one can reflect on the potential for a pest or disease to wipe out whole crops because only one variety is typically used, the impact of deforestation as an approach to tree harvesting on a region's response to various ecological events such as drought or flooding, or the capacity of reduced genetic biodiversity for creating robust species that can survive various blights because there is sufficient variety. Such systems fundamentally lack the resilience necessary to survive new stressors or systemic disruptions, creating a broadbased sustainability crisis with many different manifestations.

Monoculture, like AIG, represents a tightly interconnected system that fosters a reduction in biodiversity along with an increase in the scale and scope of human-created systems, and thus a consequent increase in system rigidity. The problem is that societally and ecologically, there are many such systems today as species extinction increases and biodiversity declines (McKibben, 2010, 2012). There is also an increase in system vulnerability to what during the financial collapse of 2008 was called systemic risk, that is, the risk of system failure. Each of these issues is itself a wicked problem because all of the subsystems are interlinked. For example, food supply and growing systems are connected to multiple other systems: the use of land resources, fertilizers (and consequent pollution), distribution, sales, marketing, pricing, and a huge range of other systems and stakeholders involving just about everyone. The larger and more central any given actors within such systems are, the more dependent the system is on the health of those actors and their ability to rebound when something goes awry. On the other hand, when there are numerous smaller actors, complexity increases but system vulnerability to systemic risk decreases because there is sufficient variety such that no single element can affect the overall health of the system if it fails. 
Many industrial practices that affect the ecosystem-and hence sustainability-today have emphasized scale and scope, along with efficiency, which typically means reducing complexity-and thereby increasing vulnerability. There are many stakeholders in these systemsbecause change is itself a wicked problem and because growth in size and scale has seemed like a good thing that will enhance profitability, an emphasis on constant growth has seemed reasonable up to now in most industries. Combined with efficiency motives, however, the result is a seeming reduction in complexity that greatly increases the system's potential to collapse (Diamond, 2005). For one industrial/ecological example, think of the impact of the purportedly efficient technique of large-scale ocean trawling, which not only scoops up desired species but any others in the way as well, and leaves huge swaths of the ocean bottom devastated. Not only does such a practice risk depleting particular species and causing the collapse of fisheries, it also causes other significant ecological damage.

A new approach to ensuring planetary (and also local) system health is clearly needed, both ecologically and socially. Perhaps, however, what is needed is not a "super" solution to the superwicked problem of sustainability but rather numerous local and diverse small scale solutions to create better system resilience, as will be argued below. Size, scale, scope, and even efficiency are problematic for system resilience and diversity because of unavoidable interconnections that are seldom recognized in the management literature, but which have become more recognizable as formerly clear boundaries have begun evaporating. Improving system resilience by improving diversity and reducing the scale and scope of large entities so that none are "too big to fail" can also enhance system adaptability (Avery \& Hughes, 2012). Such solutions are not necessarily easy to attain because of the complexity involved, and because large-scale social change is difficult and creates the need to be open to multiple perspectives and compromise, nor, as Levin and colleagues (Levin et al., 2012) note, are one-shot resolutions likely to be effective (Rittel \& Webber, 1973), particularly when developing future-facing policies.

If the problem is really one of scope and scale, then arguably one approach to dealing with the problem of boundary-reduced connectedness is enhancing system resilience. More system resilience necessarily then means developing and supporting the existence of numerous smaller and more diverse entities rather than fostering ever-larger and more dominant entities, whether organizational, institutional, or ecological. Resilience in social-ecological systems has been defined by Holling as "the persistence of relationships within a system and [as] a measure of the ability of these systems to absorb changes of state variables, driving variables, and parameters, and still persist" (Holling, 1973). That is, 
resilience is the ability of a social or ecological ecosystem to respond to changes without harm and with an ability to quickly improve or return to its usual state (even if that state is one of flux) (see Holling, 1973). Following up on this early thinking on resilience, Walker, Holling, Carpenter \& Kinzig (2004) identify three characteristics of optimal socialecological systems: 1) resilience, 2) adaptability (how actors in a system influence it), and 3) transformability (the capability to fundamentally transform when necessary).

Managing for resilience essentially emphasizes creating adaptability and diversity, or, as Holling (1973) originally put it, keeping options open. At the same time, leaders dealing with wicked problems need to keep an eye on the reality that because future events cannot necessarily be predicted, the whole system cannot be reliant on any single given system or so stressed that it collapses when a new stressor is added (cf. Diamond, 2005; Holling, 1973). In a resilient ecological or economic system, smaller and more diverse entities exist with differing agendas and can thus deal with various aspects of the problem. Since single entities are unlikely to provide acceptable solutions to a wicked problem, collaboration across organizations becomes an imperative if the system as a whole is to improve, even though collaboration requires significant adaptation by all partners (Kolk, Van Tulder, \& Kostwinder, 2008; Seitanidi, 2008; Van Tulder \& de Rosa, 2011). By creating more diversity and smaller scale systems, different enterprises can potentially deal with different aspects of the problem, although it may be harder to get at holistic systemic solutions. On the other hand, greater diversity and resilience means that is more difficult for any one event to upend the entire system, even when boundaries are diminished and entities remain tightly interconnected.

Smaller initiatives and enterprises mean that no one system becomes, as the logic went in the 2008 global financial crisis when numerous large financial institutions were bailed out, "too big to fail." Since smaller entities are locally rooted, the issues of sustainability potentially become less of a wicked problem: fewer resources are commanded by any one smaller entity compared to huge ones, and resource demands can be lessened through locality and rootedness, which make leaders more sensitive to local conditions and constraints. A diversity of responses that attempt to build resilience can be found in the emergence of relatively new initiatives like "local living economies," regionalization vs. globalization (Korten \& New Economy Working Group, 2010), "slow food" vs. mass-produced, highly processed "food products," organic farming vs. monocultural industrial farming (Pollan, 2007), and the fostering of

${ }^{5}$ BALLE, the Business Alliance for Local Living Economies, http://www. livingeconomies.org/ (accessed Sept. 15, 2011). 
plenitude (Schor, 2010) or wellbeing (Waddock \& McIntosh, 2011) vs. financial wealth alone.

Enhancing system resilience improves the overall health of a system and its ability to rebound from stressors. Simultaneously, it increases overall system complexity, escalating the need for coordination, understanding, and leadership innovation across various types of enterprises and organizations - that is, wicked good leadership. System resilience also creates more manageability of the system because each enterprise is dealing with a smaller element of the problem and has a relatively smaller impact (whether it succeeds or fails). Because it increases complexity, however, it also increases the need for collaboration across what boundaries do exist and for coordination of the whole, and puts new and quite different demands on leaders in all types of entities. That is, this approach attempts to reduce the scope and scale of boundary-less wicked problems by creating a far more diverse array of smaller enterprises to deal with them. This reduced scope and scale, and perhaps increased speed, enhance the adaptability of various elements of the system to change, thus generating more resilience.

Arguably, collaboration across what used to be societal/ecological boundaries can create new and emergent understandings of differences and potential solutions that might exist, particularly as societies begin to better understand the nature of the "too big to fail" problem created by mass scale industrialization and globalization practices. Such collaborative efforts require new ways of understanding and the generation of different types of knowledge than are typically used in one-sector settings, e.g., broad knowledge bases with knowledge that can be put to work in a different setting than that which is normally applied, along with on-going and continuous learning (Weber \& Khademian, 2008), much as happens in quality management programs, albeit in a considerably more complex context. Smaller scale solutions, even to superwicked problems, are by their nature easier to achieve than global solutions, yet a common vision and set of values around the need for sustainability is necessary even at that level. Developing such solutions locally may well create a fertile field for the development of the types of "wicked good" collaboratively oriented leaders that will be needed as local efforts scale to regional and global levels in the effort to achieve overall sustainability.

\section{Wicked (Good) Solution 2: Wicked (Good) Leaders}

Since wicked problems are complex, ambiguous, indeterminate, and boundary-less, and since enhancing system resilience calls for greater 
diversity and hence complexity, leadership and action approaches inherently more collaborative than is considered typical today will be needed. In dealing with unbounded systems or more diverse and resilient systems, top down, authoritarian leadership is considerably less likely to be effective than more open, inquiry-based, and collaborative styles of leadership that engage multiple stakeholders (Beinecke, 2009; Grint, 2005; Marshak, 2009; Roberts, 2000). In general, leaders in the $21^{\text {st }}$ century need skills that go way beyond the traditional "heroic" view of leadership (Raelin, 2003) which many people still hold. Beinecke (2009) summarizes the work of numerous scholars articulating many of these skills, which include entrepreneurial ability, priority setting, conceptualizing, surfacing assumptions, and facilitating action rather than dictating it, all helpful in dealing with wicked problems. Beinecke also notes that several skill sets are particularly important when dealing with wicked problems in the policy sector, including personal skills and knowledge (emotional intelligence, values, reflection), interpersonal skills (people skills), transactional skills (execution), transformational skills (e.g., visioning), and program knowledge (Beinecke, 2009).

Roberts (2000) argues that wicked problems, which she calls Type 3 problems, can be approached using three different types of strategies: 1) authoritative, 2) competitive, and 3) collaborative. She further argues that such problems are difficult to resolve without collaborative approaches because of the many different stakeholders and points of view that need to be brought to some degree of agreement before an approach to resolution can be generated. Authoritative strategies place the problem in a few hands that have the authority to make a decision, but doing so can create problems when expertise fails to deal with the fundamental reasons for the problem's existence.

Competitive or win/lose strategies use a zero-sum approach to determine who has the right/authority and, ultimately, the power to define the issue and attempt a resolution (i.e., through war). In a business context, competition can generate innovation, but also a degree of violence or moral problems related to the use and abuse of power (Roberts, 2000). Roberts (2000: 12) argues, however, that "people have to fail into collaboration," ultimately learning that other approaches will not work-and thus be willing to take the time and difficult steps necessary in order to collaborate. Senge (1990) further noted that dealing with such issues requires "getting the whole system in the room" (also Roberts, 2000: 13), which means bringing together stakeholders with multiple perspectives. This task is magnified in more diverse and resilient systems since there are likely to be many more stakeholders with competing perspectives, particularly around wicked problems. It also requires taking a longer- 
rather than a short-term perspective and having a future-orientation, or what Levin et al. (2012) call applied forward reasoning.

Grint (2005) provides a framework around leadership for dealing with different types of problems, ranging from critical (urgent and important), to "tame" or tractable problems with answers (see also Rittel \& Webber [1973], who coined this term), to wicked problems. Grint further argues that leadership styles necessarily move from the use of so-called hard power to using soft power (Keohane \& Nye, 1998) as leaders move through this continuum, which moves from more authoritarian unilateral approaches to demanding, as Roberts (2000) has pointed out, more collaborative solutions (Grint, 2005). While leaders using hard power provide answers, leaders using a mix of hard and soft power focus on designing processes.

Leaders using soft power ask questions or make inquiries (e.g., Torbert and associates, 2004) rather than give commands or directions. Hard power implies the ability to use coercion to get others to do what you want, while soft power rests on a leader's capacity to convince others that what she/he wants is also what they want, or to "achieve goals through attraction rather than coercion" (Keohane \& Nye, 1998). Creating the attractor has become more instantaneous and complex in the digital age of information overload, transparency, and immediacy, where credibility is crucially important yet more difficult to come by (Keohane \& Nye, 1998).

One approach to wicked problems is to re-frame and re-vision the problem in ways that stakeholders identify with. A possible strategy is to move up at least one level of analysis, i.e., from organizational to societal, as this article attempts to do, and develop an understanding of the systemic issues at play. One set of leadership skills that is needed, therefore, in the diminished boundary world of wicked problems is excellence in systems thinking, which encompasses a capacity to deal with complexity and understand the system and its interrelationships and interconnections as a whole.

Systems thinking is a basis for a good diagnosis of systemic issues. It needs to be combined with an excellent ability to listen, synthesize, and make connections across ideas, people, and approaches, and an understanding of how change happens in organizations, society, and systems in general, which fundamentally means developing skills in working collaboratively. The need to "get the system into the room" (Roberts, 2000; cf. Marshak, 2009) to effect change also means that multiple perspectives will be present in any successful collaborative effort and thus need to be integrated or coalesced in some way for action to 
take place. Networks of different types of actors and perspectives are by definition involved in dealing with wicked problems (Levin et al., 2012; Sørensen \& Torfing, 2009; Weber \& Khademian, 2008), which means that the ability to contend with differences in approaches, opinions, and ideas is necessary. Furthermore, how a given problem is framed is an important element in determining what approaches will eventually be used to try to deal with it.

The "irreversibility" of starting along a given path when dealing with wicked problems (Rittel \& Webber, 1973) means that the stakes are always high when solutions are being developed and framing is being done, and so once a system diagnosis for dealing with a wicked problem is achieved, someone needs to frame both the issue and the proposed way forward in an understandable, compelling, and generative way which allows others to feel that they have been heard and thus to buy into the framing. This skill is essentially that of applying an aesthetic or design sensibility to the wicked problem which helps shape and define it, while providing some degree of boundedness to the problem which makes it appear approachable.

The ability to create a positive or constructive vision of the way forward draws in and attracts participations to the solution. Vision rises above the level and type of thinking that generated the current problem in order to find more holistic, integrative, creative, innovative, and new ways of framing it and of envisioning new paths forward. As Einstein famously stated, "You can't solve a problem from the same level of thinking that created it." Sometimes this vision can be achieved collectively, although doing so requires the ability to effectively integrate others' points of view into a coherent vision.

Conflict resolution skills are also important. The boundary-less nature of wicked problems, especially in more resilient systems, means that different stakeholders will bring their own perspectives and their own diagnoses to the situation, so there will likely be multiple points of view on what is wrong and what the best solution is. Various diagnoses also mean that there is likely to be at least implicit conflict in getting to a solution, even when collaborative methods like Future Search, Appreciative Inquiry, World Café, scenario analysis, or mind mapping are employed; thus, leaders dealing with wicked problems collaboratively need to have high emotional intelligence and sound conflict resolution skills, and a willingness to be open to others' perspectives and incorporate them into what Buddhists call "third way thinking" (Senge, 1990). Furthermore, there needs to be a capacity and willingness to initiate action once the framing and input from multiple perspectives has been done. 
Despite the complexity and lack of apparent efficiency associated with their use, collaborative strategies are the preferred means of coping with ill-bounded wicked problems (Roberts, 2000), necessitating what some call a collaborative mindset (Weber \& Khademian, 2008). Collaboration produces better and more considered outcomes that participants with differing perspectives agree to, allows for risk-sharing and co-creation of solutions, spreads the burden among participants, and can point to redundancies that need to be eliminated (Roberts, 2000; Batie, 2008).

Since wicked problems pose questions about "what ought to be" rather than "what is" (Batie, 2008), they either explicitly or implicitly raise issues around values-and whose values will take precedent-as stakeholders grapple with them. The ability to cope with and integrate contested values-finding what is common among them-thus becomes an important leadership skill in dealing collaboratively with wicked problems. This capacity assumes a high degree of what Werhane (1999, 2002 , 2008) calls moral imagination, that is, an awareness of and sensitivity to the moral and values-related issues inherent in any decisions around a wicked problem.

Collaborative approaches can also be both self-organizing and coevolutionary (Roberts, 2000), but most people are either not familiar or comfortable with such approaches as they require patience and a willingness not to be in control all the time. Roberts points out that in collaboratively dealing with wicked problems, leaders have to learn to "trust the process," experiment, and make necessary (adaptive) changes along the way (Roberts, 2000: 15), and such an assessment is certainly true for a system attempting to achieve resilience. Wicked good leaders, then, need to function effectively in collaboration, particularly when the issue is the long-term viability of human civilization due to sustainability issues. From a developmental perspective, these capabilities imply a post-conventional level of cognitive (and probably moral) development in which systems thinking and perspective-taking is a given (Beck \& Cowan, 2005; Gilligan, 1982; Kohlberg, 1976; Wilber, 2000, 2001).

\section{CONCLUSION}

What makes the wicked problem of sustainability so difficult to deal with, in addition to population growth, are two crucial imperatives that currently drive the economic system. The first is the premise of constant growth, e.g., in consumption of material goods and financial wealth, as well as in size and efficiency, which ecologists tell us is impossible in a 
resource-constrained world (Ehrenfeld, 2008). The second is the reality that the world's economic and political systems are driven by short term considerations revolving largely around the "now," while ecological and systemic considerations are long-term in nature. Generating greater system resilience means shifting these seeming imperatives significantlyan exceedingly difficult task. Since most ecologists and climate change scientists believe that time is of the essence in shifting the system toward less growth, then perhaps it is time to engage more completely with business schools, public policy programs, and other educational institutions on the nature of the leadership that will be required in the future. Major funding institutions such as governments, multilateral institutions, aid organizations, and foundations can be encouraged to create or fund programs that develop leaders with these new skills, as, for example, the group 50+20 is trying to do with business schools, and the Centre for Responsible Leadership is attempting to do in Africa at the University of Pretoria. Collaborative problem solving suffers from the disadvantage of increased transaction costs, e.g., time, efficiency, complexity, as well as the potential for conflict surfacing among participants. It is more complicated and necessarily takes longer to effect a proposed collaborative solution than it would take for an individual to make a decision. Emerging leaders need to understand these dynamics and be equipped with the skills necessary to successfully contend with them.

Sustainability, as noted above, demands greater system resilience in a whole spectrum of systems, as well as a shift of mindset away from growth at all costs, better understanding of resource constraints, and a whole spectrum of other issues. While governmental policies could conceivably foster greater resilience by limiting huge enterprises and institutions, thereby creating more numerous and more diverse entities that enhance system resilience and, as a by-product, reduce resource use (Ehrenfeld, 2008; McKibben, 2010), it will take foresight and courage to do so in the face of a financial/industrial system resistant to change, however much it claims to be moving toward sustainability. Supporting smaller, socially-oriented enterprises and encouraging them to work locally or regionally in connected networks that are loosely rather than tightly coupled (Weick, 1976) may help with the organizational resilience issue, although the ecological issue of diversity and species loss is more problematic. Smaller enterprises that use more eco-friendly policies, however, such as the organic farming approaches discussed by Pollan (Chevat \& Pollan, 2009; Pollan, 2007), the leasing rather than selling policies (Hawken, 1993; Hawken, Lovins, \& Lovins, 1999) discussed in the Ecology of Commerce, or deliberately employed servicization and dematerialization strategies (Waddock \& McIntosh, 2011), may have approaches that place less ecological stress on the natural environment and thereby help enhance ecological resilience. 
One approach is for policy makers, company strategists, and civil society enterprises to simply start doing something that can potentially effect change, i.e., encourage entrepreneurship and innovation at a reasonable or small scale organizationally. Leaders who are more collaborative can encourage insights and input from a far wider variety of sources-and thereby have the potential to incorporate much better ideas that are "crowd sourced" into their planning (Surowiecki, 2005). If supported by governmental policies that encourage job growth and local sustainability, which is actually where the needs are, rather than simply size or financial growth, small and medium-scale enterprises (SMEs) could be encouraged over massive enterprises via tax and other policies.

For leaders to cope effectively with sustainability and create greater system resilience, they need to act with wisdom. Wisdom integrates three main attributes: 1) systems understanding (the true), 2) moral imagination (the good), and 3) aesthetic sensibility (the beautiful) (Waddock, 2010). To illustrate these linkages, the increased diversity associated with organic farming (Pollan, 2007) results in greater resilience of the land, a healthier and less abusive lifestyle for animals, and better food. This combination of effects is an aesthetically pleasing design solution to the problem of industrial farming, even though it may create more work for the farmer (although given the global scarcity of productive jobs, it is not clear that the more-work aspect is a bad outcome). Furthermore, monoculture agriculture depletes soils, creates the possibility of crop decimation because of disease, pollutes rivers, streams, and lakes from runoff, and produces crops of increasingly less nutritional value. Industrial animal production, as documented in Fast Food Nation and elsewhere (Pollan, 2007; Schlosser, 2001), is harmful to the animals, requires extensive use of antibiotics to prevent disease, and has huge ecological consequences associated with waste. Organic farming, on the other hand, creates a more diverse and productive environment, i.e., a healthier and more resilient farm, where the notion of "waste equals food" is approached (Hawken, 1993).

Collaborative solutions are difficult to manage because of their complexity, at least as compared to authoritative solutions where one person or entity presumably has "the" answer (Roberts, 2000). As must be clear from the complexity of the sustainability crisis, however, there is no one good solution. There are, and must be, numerous solutions that potentially enhance system resilience, inputs that are allowed for by collaborative approaches. Overall, the social-ecological situation looks bleak unless leaders can (relatively quickly) develop more collaborative approaches that bring together people and organizations that once thought they could resolve issues single-handedly. 
None of these suggestions, or any other that might be generated, will be easy because a massive shift in the orientation of economic and political systems is necessary in order to deal with the complexity of the sustainability crisis. It is clear that the sustainability problems faced by humanity today are so difficult and complex, so wicked and messy, that neither single entities nor single solutions are likely to resolve themthey are indeed wicked problems. But, as Marshak (2009) points out, the word "wicked" also has the modern connotation of excellence. Humanity can thus benefit from that sense of excellence by focusing on the need for wicked (good) solutions in the context of creating system change and resilience in order to cope with wicked problems, and wicked (good) leadership in order to cope with the boundary-less conditions now rampant in the world.

\section{REFERENCES}

Ackoff, R. L. 1974. Redesigning the future: A systems approach to societal problems. New York: Wiley.

Austin, J. E., \& Seitanidi, M. M. 2011. Social enterprise series no. 32: Value creation in business-nonprofit collaborations. Working papers 1-94, Harvard Business School Division of Research, Boston, MA.

Avery, G. C., \& Hughes, B. 2012. Sustainable leadership: Fresh thoughts. Prahan, Australia: Tilde University Press.

Batie, S. S. 2000. Wicked problems and applied economics. American Journal of Agricultural Economics, 90(5): 1176-1191.

Beck, D., \& Cowan, C. C. 2005. Spiral dynamics: Mastering values, leadership and change: Explaining the new science of memetics. Oxford: Blackwell.

Beinecke, R. H. 2009. Introduction: Leadership for wicked problems. Innovation Journal, 14(1): 1-17.

Brown, L. R., Brown, L. R., Plan B 3.0, \& Earth Policy Institute. 2009. Plan B 4.0:

Mobilizing to save civilization (1st ed.). New York: Norton.

Brundtland Commission. 1987. Our common future: Report of the World Commission on Environment and Development, http://www.un.org/ documents/ga/res/42/ares42-187.htm (accessed June 10, 2013).

Chevat, R., \& Pollan, M. 2009. The omnivore's dilemma: The secrets behind what you eat. New York: Dial Books.

Churchman, C. W. 1967. Wicked problems. Management Science, December, 15(4): B141-B142.

Diamond, J. M. 2005. Collapse: How societies choose to fail or succeed. New York: Viking.

Durant, R. F., \& Legge, J. S. 2006. "Wicked problems," public policy, and administrative theory lessons from the GM food regulatory arena. Administration \& Society, 38(3): 309-334. 
Ehrenfeld, J. 2008. Sustainability by design: A subversive strategy for transforming our consumer culture. New Haven: Yale University Press.

Emerson, J. 1999. Leadership of the whole: The emerging power of social entrepreneurship. Leader to Leader, 13: 12-14.

Emerson, J. 2003. The blended value proposition: Integrating social and financial results. California Management Review, 45(4): 35-51.

Ferlie, E., Fitzgerald, L., McGivern, G., Dopson, S., \& Bennett, C. 2011. Public policy networks and "wicked problems": A nascent solution? Public Administration, 89(2): 307-324.

Gilding, P. 2011. The great disruption: Why the climate crisis will bring on the end of shopping and the birth of a new world. New York: Bloomsbury.

Gilligan, C. 1982. In a different voice: Psychological theory and women's development. Cambridge, MA: Harvard University Press.

Grint, K. 2005. Problems, problems, problems: The social construction of "leadership." Human Relations, 58(11): 1467-1494.

Hart, S. L. 2006. Worlds in collision. Journal of Organizational Excellence, 25(3): 13-25.

Hart, S. L. 2007. Capitalism at the crossroads: Aligning business, earth, and humanity. Upper Saddle River, NJ: Wharton.

Hawken, P. 1993. The ecology of commerce: A declaration of sustainability (rev. ed.). New York: Harper Business.

Hawken, P., Lovins, A. B., \& Lovins, L. H. 1999. Natural capitalism: Creating the next industrial revolution (1st ed.). Boston: Little, Brown and Co.

Holling, C. S. 1973. Resilience and stability of ecological systems. Annual Review of Ecology and Systematics, 4: 1-23.

Intergovernmental Panel on Climate Change. 2007. Fourth assessment report, climate change 2007: Synthesis report: Summary for policymakers, http://www.ipcc.ch/pdf/assessment-report/ar4/syr/ar4_ syr_spm.pdf (accessed June 10, 2013).

Jackson, T. 2012. Prosperity without growth: Economics for a finite planet. New York: Routledge.

Keohane, R. O., \& Nye Jr., J. S. 1998. Power and interdependence in the information age. Foreign Affairs, 77(5): 81-94.

Kohlberg, L. 1976. Moral stages and moralization: The cognitive-developmental approach. In Moral development and behavior: Theory, research, and social issues: $31-53$. New York: Holt, Rinehart and Winston.

Kolk, A., Van Tulder, R., \& Kostwinder, E. 2008. Business and partnerships for development. European Management Journal, 26(4): 262-273.

Korten, D. C., \& New Economy Working Group. 2010. Agenda for a new economy: From phantom wealth to real wealth (2nd ed.). San Francisco: BerrettKoehler Publishers.

Levin, K., Cashore, B., Bernstein, S., \& Auld, G. 2012. Overcoming the tragedy of super wicked problems: Constraining our future selves to ameliorate global climate change. Policy Sciences, 45(2): 123-152. 
Marshak, R. J. 2009. Reflections on wicked problems in organizations. Journal of Management Inquiry, 18(1): 58-59.

Matten, D., \& Crane, A. 2005. Corporate citizenship: Toward an extended theoretical conceptualization. Academy of Management Review, 30(1): 166-179.

Matten, D., Crane, A., \& Chapple, W. 2003. Behind the mask: Revealing the true face of corporate citizenship. Journal of Business Ethics, 45(1): 109-120.

McKibben, B. 2010. Eaarth: Making a life on a tough new planet (1st ed.). New York: Times Books.

McKibben, B. 2012. Global warming's terrifying new math. Rolling Stone, http:// cambioclimatico-bolivia.org/archivos/20120813060654_0.pdf (accessed June 10, 2013).

Moon, J., Crane, A., \& Matten, D. 2005. Can corporations be citizens? Business Ethics Quarterly, 15(3): 429-453.

Pollan, M. 2007. The omnivore's dilemma: A natural history of four meals. New York: Penguin.

Porter, M. E., \& Kramer, M. R. 2011. The big idea: Creating shared value. Harvard Business Review, 89(1-2): 62-77.

Prahalad, C. K. 2005. The fortune at the bottom of the pyramid. Upper Saddle River, NJ: Wharton.

Prahalad, C. K., \& Hammond, A. 2002. Serving the world's poor, profitably. Harvard Business Review, 80(9): 48-57.

Raelin, J. A. 2003. Creating leaderful organizations: How to bring out leadership in everyone (1st ed.). San Francisco, CA: Berrett-Koehler.

Rittel, H. W., \& Webber, M. M. 1973. Dilemmas in a general theory of planning. Policy Sciences, 4(2): 155-169.

Roberts, N. 2000. Wicked problems and network approaches to resolution.

International Public Management Review, 1(1): 1-19.

Schlosser, E. 2001. Fast food nation: The dark side of the all-American meal. Boston: Houghton Mifflin.

Schor, J. 2010. Plenitude: The new economics of true wealth. New York: Penguin Press.

Schumpeter, J. A. 1962. Capitalism, socialism, and democracy (3rd ed.). New York: Harper \& Row.

Seitanidi, M. M. 2008. Adaptive responsibilities: Non-linear interactions across social sectors: Cases from cross sector partnerships. Emergence: Complexity and Organization, 10(3): 51-64.

Senge, P. M. 1990. The fifth discipline: The art and practice of the learning organization. New York: Doubleday.

Senge, P. M., Smith, B., Kruschwitz, N., Laur, J., \& Schley, S. 2008. The necessary revolution: How individuals and organizations are working together to create a sustainable world. New York: Crown Business.

Sørensen, E., \& Torfing, J. 2009. Making governance networks effective and democratic through metagovernance. Public Administration, 87(2): 234-258.

Surowiecki, J. 2005. The wisdom of crowds. Norwell, MA: Anchor. 
Torbert, W. R. and associates. 2004. Action inquiry: The secret of timely and transforming leadership. San Francisco: Berrett-Koehler.

van Bueren, E. M., Klijn, E., \& Koppenjan, J. F. M. 2003. Dealing with wicked problems in networks: Analyzing an environmental debate from a network perspective. Journal of Public Administration Research \& Theory, 13(2): 193-212.

Van Tulder, R., \& de Rosa, A. 2011. Partnerships Resource Center: The state of partnership report 2010: How the world's leading corporations are building up a portfolio of cross sector partnerships. Rotterdam, The Netherlands: The Partnerships Resource Center.

Waddell, S. 2003. Global action networks: A global invention helping business make globalisation work for all. Journal of Corporate Citizenship, 12: 27-42.

Waddell, S. 2009. Global action networks: An organizational innovation. Reflections, 9(3-4): 1-14.

Waddock, S. 2010. Finding wisdom within-the role of seeing and reflective practice in developing moral imagination, aesthetic sensibility, and systems understanding. Journal of Business Ethics Education, 7(1): 177-196.

Waddock, S. 2011. We are all stakeholders of Gaia: A normative perspective on stakeholder thinking. Organization \& Environment, 24(2): 192-212.

Waddock, S. A., \& McIntosh, M. 2011. SEE change: Making the transition to a sustainable enterprise economy. Sheffield, U.K: Greenleaf.

Walker, B., Holling, C. S., Carpenter, S. R., \& Kinzig, A. 2004. Resilience, adaptability and transformability in social-ecological systems. Ecology and Society, 9(2): 5.

Weber, E. P., \& Khademian, A. M. 2008. Wicked problems, knowledge challenges, and collaborative capacity builders in network settings. Public Administration Review, 68(2): 334-349.

Weick, K. E. 1976. Educational organizations as loosely coupled systems. Administrative Science Quarterly, 21(1): 1-19.

Werhane, P. H. 1999. Moral imagination and management decision-making. New York: Oxford.

Werhane, P. H. 2002. Moral imagination and systems thinking. Journal of Business Ethics, 38(1): 33-42.

Werhane, P. H. 2008. Mental models, moral imagination and system thinking in the age of globalization. Journal of Business Ethics, 78(3): 463-474.

Wilber, K. 2000. Integral psychology: Consciousness, spirit, psychology, therapy. Boston: Shambhala Publications.

Wilber, K. 2001. A theory of everything: An integral vision for business, politics, science, and spirituality. Dublin: Gateway. 
